\title{
APLICAÇÃO DO MODELO SERVPERF PARA AVALIAÇÃO DOS SERVIÇOS OFERECIDOS PELO RESTAURANTE ALBINOS NO MUNICÍPIO DE ITAPERUNA/RJ
}

\section{APPLICATION OF THE SERVPERF MODEL TO EVALUATE THE SERVICES OFFERED BY THE ALBINOS RESTAURANT IN THE MUNICIPALITY OF ITAPERUNA / RJ}

\author{
Jennifer de Araujo Freitas* E-mail: jenniferaraujofreitas@gmail.com \\ Paola Amorim Silva* E-mail: paooola.a@hotmail.com \\ Fabio Freitas da Silva* E-mail: fabio1 freitas@hotmail.com \\ Alzeleni Pio da Silva Tavares Corrêa* E-mail: alzelenitavares@yahoo.com.br \\ Aldo Shimoya* E-mail: aldoshimoya@yahoo.com.br \\ Eduardo Shimoda*E-mail: shimoda@ucam-campos.br \\ *Universidade Candido Mendes (UCAM), Rio de Janeiro, RJ
}

Resumo: O objetivo desse trabalho é analisar a importância da percepção da qualidade do serviço prestado pelo restaurante Albinos no município de Itaperuna RJ. Para fundamentar esse trabalho, elaborou-se uma pesquisa de satisfação do cliente, levando em consideração o atendimento prestado, a qualidade do serviço, rapidez do processo de entrega, confiabilidade, conforto, segurança e preço. $O$ levantamento de dados ocorreu por meio da elaboração de um questionário baseado em estudos científicos e nas dimensões do modelo de desempenho de serviço SERVPERF, utilizando a escala Likert de 5 pontos. O estudo teve como objetivo comprovar que embora a satisfação do cliente dependa de um conjunto de fatores, o atendimento direto ao cliente pode se tornar um dos maiores diferenciais na hora de prestar um serviço ou atendimento ao cliente, tendo como base os princípios éticos e morais, seguido de cortesia e empatia. Com base nos dados foi possível avaliar e quantificar a qualidade dos serviços sob a visão dos clientes e sugerir propostas de melhorias para que a empresa atinja vantagem competitiva.

Palavras-chave: Qualidade de Serviços, Marketing de Relacionamento, SERVPERF, Questionário.

Abstract: The objective of this work is to analyze the importance of the perception of the quality of the service provided by the restaurant Albinos in the municipality of Itaperuna RJ. In order to base this paper, a customer satisfaction survey was developed, taking into consideration the service provided, the quality of the service, speed of the delivery process, reliability, comfort, safety and price. Data collection was carried out through the elaboration of a questionnaire based on scientific studies and the dimensions of the SERVPERF service performance model, using the 5-point Likert scale. The study aimed to prove that although customer satisfaction depends on a set of factors, direct customer service can become one of the biggest differentials in providing a service or customer service, based on ethical and moral principles, followed by courtesy and empathy. Based on the data, it was possible to evaluate and quantify the quality of the services under the clients' vision and to suggest proposals for improvements so that the company achieves competitive advantage.

Keywords: Quality of Services. Relationship Marketing. SERVPERF. Questionnaire. 


\section{INTRODUÇÃO}

O cenário em que as empresas estão inseridas tem se tornado cada vez mais competitivos, desse modo, os efeitos da competição obrigam as empresas a buscarem métodos gerenciais para a sobrevivência no mercado. Cada vez mais organizações compreendem que a sua base de clientes e o ativo mais valioso (SCHULZE; SKIERA; WIESEL, 2012). Sendo assim, com o intuito de alcançarem as metas estabelecidas, as empresas precisam estar centradas no cliente. Segundo Kotler (2000, p.55), "Já não basta simplesmente satisfazer os clientes, é preciso encantá-los".

Em todo mundo, várias organizações dedicam-se a analisar e aplicar o marketing de relacionamento, sob a perspectiva de satisfação dos clientes. De acordo com Kotler e Armstrong (2003, p.3) "A função do marketing, mais do que qualquer outra nos negócios, é lidar com os clientes. Entender, criar, comunicar e proporcionar ao cliente valor e satisfação constitui a essência do pensamento e da prática do marketing moderno". Para Kotler (2000, p.58) "Satisfação consiste na sensação de prazer e desapontamento resultante da comparação do desempenho (ou resultado) percebido de um produto em relação às expectativas do comprador". $O$ atendimento oferecido é a principal ferramenta de uma organização para conquistar o cliente, considerando que a qualidade desses serviços é imprescindível para o resultado final. Segundo Fitzsimmons J e Fitzsimmons M (2011, p.139) "Cada contato com um cliente é referido como sendo um momento de verdade, uma oportunidade de satisfazer ou não ao cliente".

Porter (1999) acrescenta que a satisfação dos clientes não é uma alternativa, é uma questão de sobrevivência para qualquer organização. Sendo assim, a gerência necessita buscar de maneira continua a satisfação dos clientes, considerando a alteração nas necessidades dos mesmos. Kotler (1998) acredita que um bom atendimento somado com a satisfação do cliente, é o motivo que faz com que os clientes retornem à organização. Desse modo, segundo o autor, a satisfação do cliente precisa ser o objetivo central, pois estes quando satisfeitos não são apenas clientes, e sim aliados comercias que defendem e fazem propaganda.

Nesse contexto, o objetivo deste trabalho foi avaliar os serviços de atendimento ao cliente e identificar o grau de satisfação dos clientes no Restaurante Albinos com 
relação aos serviços prestados. Isso permitiu apontar: itens críticos que devem ser priorizados em prol de melhorias dos serviços prestados; avaliar o conforto do consumidor após a prestação de serviços; e propor melhorias no atendimento e na criação de valor.

\section{REFERENCIAL TEORICO}

\subsection{A natureza dos serviços}

Kotler (1998, p.191) afirma que o serviço é: "Qualquer atividade ou benefício que uma parte possa oferecer a outra, essencialmente intangível, e que não resulta em propriedade e sua produção pode ou não estar vinculada a um produto físico".

Segundo Teboul (2008) um serviço é "uma série de atividades que normalmente acontece durante as interações entre clientes e estruturas, recursos humanos, bens e sistemas do fornecedor, com a finalidade de atender a uma necessidade do cliente".

Para Albrecth (2004) o serviço interno é tratar bem quem presta serviço. É preciso espírito de equipe e cooperação em toda a organização para que o nível de qualidade do serviço se mantenha elevado.

Atualmente, "o setor de serviços tem maior participação na economia mundial, No Reino Unido, o setor de serviços corresponde mais de $65 \%$ do Produto Interno Bruto (PIB) e nos E.U.A. o setor de serviços corresponde a mais de $75 \%$ do PIB" (TEBOUL, 2008, p.51).

De acordo com Teboul (2008), há um grande número de pessoas no setor de serviços que tende a aumentar com o passar do tempo, constatando o setor como o que mais emprega no mundo.

No Brasil também há um crescimento do setor de serviços, e é possível afirmar que a participação passou a representar mais da metade do PIB nacional chegando a mais de 50\% em 2013, segundo o Instituto Brasileiro de Geografia e Estatística (IBGE, 2015).

Para Albrecht (2004), antes de atender um cliente externo, atende-se primeiramente os clientes internos, que precisam de resultados que agreguem valor ao seu trabalho, demonstrando a relevância dos processos de apoio e gestão. A satisfação dos clientes está ligada a satisfação de seus funcionários (BALTA, 2018). 
Dessa forma, os processos de gestão devem estar estruturados para atender as necessidades de seus clientes internos e, assim, contribuir com a agregação de valor em cadeia.

Ou seja, ainda que um funcionário da linha de frente queira prestar um atendimento excelente, não é suficiente nem possível. Existe uma cadeia de qualidade que deve ser analisada e explorada para que o resultado final seja o desejado. Toda a organização deve estar em sintonia, na mesma estrutura. Pois o cliente avaliará a qualidade do serviço como um todo.

\subsection{Qualidade no serviço: uma ferramenta de competitividade}

Porter (1999) afirma que a competitividade de uma empresa no mercado está na capacidade de compatibilizar suas atividades, e isto é a essência da estratégia. Quando uma empresa consegue sintonizar todas as suas atividades de uma forma sistêmica, atinge vantagem competitiva capaz de promover rentabilidade e alto valor econômico.

Segundo Kotler e Keller (2006) a qualidade é alcançada quando satisfaz as necessidades que o cliente manifesta, mas principalmente quando supera as expectativas deles, não apenas com o produto ou serviço ofertado, mas em todo o processo. As empresas têm empregado os princípios da gestão da qualidade total Total Quality Management (TQM), para alcançar e superar satisfação do cliente. TQM de acordo com Kotler e Keller (2006, p.146) "é uma abordagem que busca a melhoria contínua de todos os processos, produtos e serviços da organização".

O TQM abrange o projeto de organizações que satisfaçam constantemente os seus clientes que possui dois elementos, a saber: Projeto cuidadoso do produto ou do serviço; Garantia de que os sistemas da organização podem produzir o produto ou serviço projetado de maneira consistente. Esses dois elementos interligados somente podem ser atingidos se toda a organização for orientada para eles. Por isso, o termo gerenciamento da qualidade total. Orientar a organização no sentido da qualidade exige muito mais do que a vontade de se tornar diferente (DRUMMOND (1998) apud PELLIM; MASHIBA; SANTOS (2010)).

Drummond (1998) apud Pellim; Mashiba e Santos (2010) explica que a mudança é um processo lento, que pode interferir até mesmo na cultura 
organizacional, pois a TQM determina que todas as ações da empresa estejam focada para a qualidade, minimizando desperdício, aumentando a produtividade, maximizando as vendas e gerando maior satisfação ao cliente. Consequentemente, pode-se dizer que a qualidade total é um meio para um fim.

Devido a isso, qualidade total é um tema que vem sido altamente abordado. Kotler e Keller (2006) evidenciam que assim como o marketing é obrigação de todas as empresas, a qualidade total deve se tornar, sendo assim, a solução para criar valor e satisfazer o cliente.

\subsection{Busca da satisfação do cliente}

Cobra (2007) conclui que os elementos do composto de marketing, os 4P's, surgiram para satisfazer o cliente. O produto deve atender as necessidades e desejo e deve ter: qualidade e padronização, em termos de características, desempenhos e acabamentos; modelos e tamanhos, que atendam às expectativas e necessidades; configuração, apresentação do produto em termos de apresentação física, embalagem, marca e serviço. O autor também afirma que o produto ou serviço deve estar posicionado junto com o seu cliente, através de canais de distribuição como: atacado; varejo ou distribuidor; transporte e armazenagem.

Sobre o preço diz: "o produto deve ser certo, deve estar no ponto certo e deve transferir a posse no preço certo". Define promoção como a publicidade, as relações públicas, a promoção de vendas pessoal e merchandising. Destacando que ela deve comunicar o produto ou serviço ao mercado, estimulando e realizando a venda.

Para Porter (1999) a liderança deve manter o processo para a busca continua da satisfação do cliente. Dessa forma, é preciso conhecer e compreender necessidades e trabalhar para atender essas necessidades. Isso exigirá a dedicação de recursos para coletar e analisar dados e informações, sistematicamente, para entender os requisitos e as percepções do cliente.

Albrecht (2004) assegura que a satisfação do cliente externo é o resultado do atendimento realizado entre as áreas no cotidiano dentro das empresas. Este é um dos grandes desafios com que às organizações contemporâneas têm de lidar e que deve começar de dentro pra fora, ou seja, da qualidade dos relacionamentos e 
serviços internos para o alcance da excelência na prestação de serviços aos consumidores.

Las Casas (2009) informa que as necessidades dos clientes mudam constantemente, assim a empresa precisa estar preparada e antecipar-se a essas mudanças para obter vantagens competitivas. Com isso, haverá um retorno positivo a médio e em longo prazo.

\subsection{As necessidades humanas}

Para Chiavenato (2005) Abraham Maslow foi um psicólogo de grande destaque por causa de seu estudo relacionado às necessidades humanas. Segundo Maslow o homem é motivado por suas necessidades que se manifestam em graus de importância onde as fisiológicas são as necessidades iniciais e as de realização pessoal são as necessidades finais. Cada necessidade humana influencia na motivação e na realização do indivíduo que o faz prosseguir para outras necessidades que marcam uma escala hierárquica.

Kotler e Keller (2006) citam que a Teoria de Maslow auxilia os profissionais de marketing a perceber como os variados produtos se moldam aos planos, objetivos e na vida dos indivíduos.

Para Maslow (1954) as necessidades humanas estão colocadas em um uma escala de importância e de influencia do comportamento humano. São dividas em cinco categorias de necessidades humanas: auto realização; estima; sociais; segurança; fisiológica.

Chiavenato (2005) explica as cinco categorias da seguinte forma: a primeira delas são as necessidades fisiológicas, que estabelece o nível mais baixo de todas as necessidades humanas, como as necessidades de alimentação, de sono e repouso, abrigo ou desejo sexual. As necessidades fisiológicas são também denominadas biológicas ou básicas e exigem satisfação cíclica e incessante para garantir a sobrevivência do indivíduo. Elas orientam a vida humana desde o momento do nascimento. Embora comuns a todas as pessoas, elas requerem diferentes gradações individuais para a sua satisfação. Quando alguma dessas necessidades não está satisfeita, ela domina a direção do comportamento. Quando todas as necessidades humanas estão insatisfeitas, a maior motivação será a das necessidades fisiológicas 
e o comportamento da pessoa terá a finalidade de encontrar alívio na pressão que essas necessidades produzem sobre o organismo humano.

A segunda delas são as necessidades de segurança, que equivale o segundo nível das necessidades humanas. Levam a pessoa a proteger-se de qualquer perigo real ou imaginário, físico ou abstrato, a busca de proteção contra a ameaça ou provocação, a fuga ao perigo, o desejo de estabilidade, a busca de um mundo ordenado e previsível são manifestações típicas dessas necessidades. As necessidades de segurança têm grande importância, uma vez que na vida organizacional às pessoas têm uma relação de dependência com a empresa e onde as ações gerenciais arbitrárias ou as decisões inconscientes e incoerentes podem provocar incerteza ou insegurança nas pessoas quanto à sua permanência no emprego.

Ainda para o autor, a terceira das necessidades são as necessidades sociais, que são as estão relacionadas com a vida social do indivíduo com outras pessoas. São as necessidades de associação, de participação, de aceitação por parte dos colegas, de troca de amizade, de afeto e amor. Surgem no comportamento quando as necessidades mais baixas (fisiológicas e de segurança) se encontram relativamente satisfeitas. Quando as necessidades sociais não estão suficientemente satisfeitas, a pessoa se torna resistente, antagônica e hostil com relação às pessoas que a cercam.

A quarta necessidade são as necessidades de estima que se refere a maneira pela qual a pessoa se vê e se avalia, isto é, auto-avaliação e a auto-estima. Envolve a necessidade de aprovação social. A satisfação dessas necessidades conduz a sentimentos de autoconfiança, de valor, força, prestígio, poder, capacidade e utilidade.

A quinta necessidade são as necessidades de auto-realização, são as necessidades humanas mais elevadas e que se encontram no topo da hierarquia. Essas necessidades levam cada pessoa a realizar o seu próprio potencial e a se desenvolver continuamente ao longo da vida. As necessidades de auto-realização estão relacionadas com a plena realização daquilo que cada pessoa tem de potencial e de virtual, da utilização plena dos talentos individuais.

Kotler (1998) reforça que a Teoria de Maslow é abordada como uma das mais importantes teorias da motivação. Para ele, as necessidades dos seres humanos obedecem a uma escala de valores a serem transpostos. Isto significa que no momento em que o indivíduo realiza uma necessidade, surge outra em seu lugar, 
impondo que as pessoas busquem recursos para satisfazê-la. Poucas, ou, nenhuma pessoa procurará reconhecimento pessoal e status se suas necessidades básicas estiverem insatisfeitas.

\subsection{Satisfação do cliente}

A satisfação do cliente está diretamente ligada às expectativas que o mesmo criou em relação ao produto ou serviço, baseado no que a ele foi apresentado e informado. Kotler e Keller (2006) explicam que satisfação é a sensação de prazer ou desapontamento resultante da comparação entre o desempenho (ou resultado) percebido de um produto e as expectativas do comprador. Se os profissionais de marketing estabelecerem expectativas muito altas, o comprador certamente ficará desapontado. Por outro lado, se a empresa estabelecer expectativas muito baixas, não atrairá compradores suficientes, porém realizará aqueles que comprarem.

Dando continuidade, Fitzsimmons A. e Fitzsimmons J. (2000, p.249) destacam "a satisfação do cliente com a qualidade do serviço pode ser definida pela comparação da percepção do serviço prestado com a expectativa do serviço desejado". Cobra e Ribeiro (2000, p.94) completam que "a satisfação e o prazer do consumidor são derivados da percepção de que os benefícios são superiores ao custo".

Las Casas (2006, p.49) aponta uma visão importante e certeira "um cliente que fica insatisfeito tende a se tornar um "terrorista". O cliente encantando torna-se um "apóstolo" e, por que não, até um vendedor da empresa. O objetivo de todos deve ser o de tornar os clientes satisfeitos como apóstolos da companhia".

Kotler e Keller (2006) constatam que é necessário medir a satisfação do cliente frequentemente para se obter um parâmetro de avaliação, pois a chave para reter clientes está em satisfazê-los. Em geral, um cliente satisfeito permanece fiel, compra mais à medida que a empresa lança novos produtos ou aperfeiçoa aqueles existentes, fala bem da empresa e de seus produtos ou serviços e custa menos para ser atendido do que um cliente novo, uma vez que as transações já se tornaram rotineiras.

Segundo Albrecht (1993), o intuito de medir algo é determinar melhorias a partir dos resultados obtidos na medição. Do ponto de vista do melhoramento da qualidade, isto significa que se podem identificar oportunidades, estabelecer uma base ou verificar as ações implementadas, gerando um maior retorno para a empresa. Há 
diversas formas para medir esse nível de satisfação dos clientes. Para Cobra e Ribeiro (2000) as principais são: Questionário oral ou por escrito ao entrevistado; entrevista pessoalmente sem questionário estruturado; por pesquisa eletrônica ou via e-mail. Para Whiteley (1996), deve-se ter em mente quem são os clientes e os cinco princípios para realizar a medição, que são: saber por que está medindo; deixar os clientes the informarem que resultados finais medir; perguntar constantemente como está o seu desempenho e o de seus competidores; acompanhar os procedimentos internos que devem produzir os resultados que os clientes desejarem assim como os resultados finais; Informar ao seu pessoal tudo que você constatar.

Um instrumento para mensurar a qualidade em serviços é a SERVQUAL que implementa o conceito de falha, isto é, a lacuna entre as expectativas e as percepções dos clientes (Fitzsimmons J; Fitzsimmons M, 2011). Segundo Albrecht (1993) não existe forma correta para medir todos os aspectos da qualidade. É necessário calcular estratégias de medição, dependendo de como o cliente define cada aspecto.

\subsection{Servperf}

Cronin e Taylor (1992) desenvolveram o modelo SERVPERF, baseado na medida de desempenho da qualidade dos serviços. Os autores afirmam que a qualidade percebida dos serviços seja um antecedente à satisfação do cliente, e que essa satisfação tem efeito significativo nas intenções de compra. Ainda segundo estes autores, a qualidade dos serviços tem uma menor influência nas intenções de compra que a própria satisfação do cliente. Esse modelo surge como uma alternativa ao instrumento SERVQUAL e pode ser expresso por:

$$
Q i=D i
$$

Sendo:

$Q \mathrm{Q}=$ Avaliação da qualidade do serviço em relação à característica i.

$\mathrm{Di}=$ Valores de percepção de desempenho para a característica i de serviço.

Para o autor Parasuraman et al. (1988) existem 10 determinantes da qualidade: confiabilidade, presteza, competência, acessibilidade, cortesia, comunicação, credibilidade, segurança, compreensão e conhecimento do cliente e aspectos tangíveis. Elas representam os pontos críticos na prestação de um serviço, que podem 
causar a discrepância entre expectativa e desempenho, e que devem ser minimizadas com objetivo de atingir um padrão de qualidade. Com o refinamento da escala, foi alcançado um resultado de cinco dimensões, caracterizadas por 22 itens, sendo as seguintes:

- Confiabilidade: capacidade de realizar um serviço prometido de forma confiável e precisa;

- Presteza: ajudar o cliente e prover pronto atendimento;

- Segurança: habilidade em transmitir confiança e segurança, com cortesia e conhecimento;

- Empatia: cuidados e atenção individualizados aos clientes;

- Aspectos Tangíveis: instalações, equipamentos, pessoal envolvido e material de comunicação.

No modelo SERVPERV, foram considerados 22 itens que representam as dimensões da qualidade em serviço proposto por Parasuraman et al. (1988), uma avaliação para cada um dos itens quanto a sua importância e um questionário adicional. Os 22 itens foram utilizados para testar as seguintes hipóteses:

- Uma medida de qualidade em serviço SERVPERF não ponderada é mais apropriada para a medição da qualidade em serviço que 0 instrumento SERVQUAL, SERVQUAL ponderado, ou SERVPERF ponderado;

- Satisfação de cliente é um antecedente da qualidade percebida do serviço;

- Satisfação do cliente tem um impacto significativo nas intenções de recompra;

- Qualidade percebida do serviço tem um impacto significativo nas intenções de recompra.

Os 22 itens são distribuídos pelas cinco dimensões anteriores, são descritos por afirmações, utilizando uma escala Likert de 7 pontos, com a seguinte classificação: (1) "discordo fortemente"; (2) "discordo"; (3) "discordo parcialmente"; (4) "não concordo nem discordo"; (5) "concordo parcialmente"; (6) "concordo"; (7) "concordo fortemente e (NA) "não avaliado", considerado abstenção. O trabalho foi aplicado em quatro prestadores de serviços em áreas diversas como: bancos, controle de pragas, lavagem de roupa a seco e lanchonete.

Os autores concluíram que o modelo SERVPERF é mais preciso em retratar as variações de qualidade em relação às outras escalas testadas, por meio da utilização de ferramentas estatísticas como o teste estatístico do qui-quadrado, prova de 
aderência das distribuições empíricas de dados e coeficiente de determinação da regressão linear dos dados.

\section{METODOLOGIA}

\subsection{Materiais e métodos}

O método utilizado se baseia na proposta dos autores Barros e Freitas (2013), chamado pelos autores de modelo DINNERPERF, que possui como objetivo avaliar e classificar a qualidade de serviços em restaurantes, considerando a percepção dos clientes. Esse modelo foi desenvolvido através da ferramenta SERVPERF. E é composto por 59 itens e por 15 dimensões, que são adaptáveis a diferentes tipos de restaurantes.

Adaptado ao questionário de Barros (2013) o instrumento proposto para realização da coleta de dados arranjou-se em quatro blocos, expostos a seguir:

Bloco 1 (Grau de percepção): É constituído pelos itens relacionados a avaliação da qualidade dos serviços, distribuídas nas 15 dimensões estabelecidas;

Bloco 2 (Grau de satisfação geral): Avalia de forma geral, o grau de satisfação quanto à empresa, de acordo com o ponto de vista do respondente;

Bloco 3 (Críticas ou sugestões): É composto por um espaço que proporciona ao respondente expressar sua opinião, sendo aberto para críticas ou sugestões;

Bloco 4 (Perfil do respondente): Identifica o perfil dos clientes, considerando alguns aspectos como: idade, gênero, nível de escolaridade, renda mensal e a frequência da utilização dos serviços de restaurantes.

Aplicou-se a escala psicométrica Likert de 5 pontos para obtenção dos dados a serem analisados através da mensuração do grau de expectativa dos itens exigindo que os respondentes indicassem um grau de concordância ou discordância em cada uma das afirmações, sendo estes: (1) Discordo totalmente, (2) Discordo, (3) Não concordo nem discordo, (4) Concordo e (5) Concordo totalmente. Além do mais, utilizou-se a alternativa de abstenção NA (Não avaliado), caso o respondente não se julgasse apto para adotar um ponto de vista sobre um determinado item (MALHOTRA, 2006). 


\subsection{Coleta de dados}

Silva e Menezes (2005) definem universo da pesquisa como sendo o total de indivíduos que possuem características similares perceptíveis para a análise. Com intuito de verificar a clareza e adequação do questionário, foi realizado um pré-teste com 15 respondentes no período de 15 a 17 de Julho de 2016. Para Malhotra (2006) o pré-teste tem objetivo de avaliar o instrumento, garantir que meça o que se pretende, com intuito de identificar e eliminar os problemas em potencial.

Para definição do tamanho da amostra foi utilizada metodologia descrita por Gil (1988). Na execução da pesquisa foi aplicado um questionário em uma amostra de 260 respondentes, com um nível de confiança de $z=94 \%$ e precisão \%= $6 \%$ no período de 18 de julho a 4 de agosto de 2016. Considerando a população de 95.841 pessoas no município de Itaperuna, segundo IBGE (2010) e aproximadamente 9000 refeições por mês, de acordo com dados do restaurante.

\subsection{Análise de dados}

Após a coleta dos dados, os mesmos foram organizados, tabulados e analisados. Para facilitar a apresentação dos resultados, foram utilizados gráficos, métodos estatísticos, tabelas de frequência, análise de perfil, erros padrão, correlação e os softwares SAEG (Sistema para Análises Estatísticas e Genéticas) e Excel.

Para verificar a confiabilidade do formulário, utilizou-se o coeficiente a de Cronbach (CRONBACH, 1951) que é uma das mais tradicionais estimativas da confiabilidade de um questionário que tenha sido aplicado em uma pesquisa. Dado que todos os itens de cada dimensão possuem a mesma escala de medição, o coeficiente $\alpha$, com $\alpha \in[0,1]$, é calculado a partir da variância dos itens individuais e das covariâncias entre os itens. A equação abaixo representa a fórmula, onde $k$ é o número de itens da dimensão, $S_{i}^{2}$ é a variância do item i e $S_{t}^{2}$ é a variância total da dimensão. 


$$
\alpha=\left(\frac{k}{k-1}\right)\left(1-\frac{\sum_{i=1}^{k} S_{i}^{2}}{S_{t}^{2}}\right)
$$

O coeficiente de Cronbach é um dos procedimentos estatísticos mais utilizados para calcular a confiabilidade de um questionário para avaliação do objeto a que se destina (FREITAS; RODRIGUES, 2005). Segundo os mesmos autores, no meio científico não há um consenso a respeito da interpretação da confiabilidade de um questionário a partir desse coeficiente e sugerem uma classificação para tratar essa questão conforme mostra o Quadro 1.

Quadro 3 - Classificação da confiabilidade a partir do a de Cronbach

\begin{tabular}{|l|l|}
\hline Valor de $\alpha$ & Confiabilidade \\
\hline$\alpha \leq 0,300$ & Muito baixa \\
\hline $0,300<\alpha \leq 0,600$ & Baixa \\
\hline $0,600<\alpha \leq 0,750$ & Moderada \\
\hline $0,750<\alpha \leq 0,900$ & Alta \\
\hline$\alpha>0,900$ & Muito Alta \\
\hline
\end{tabular}

Fonte: Adaptado de Freitas e Rodrigues (2005)

\section{RESULTADOS}

\subsection{Perfil dos Clientes}

Encontra-se nas Figuras 1 e 2, os dados sociodemográficos dos clientes do Restaurante Albinos e uma visão geral da amostra.

Figura 1 - Gênero dos respondentes

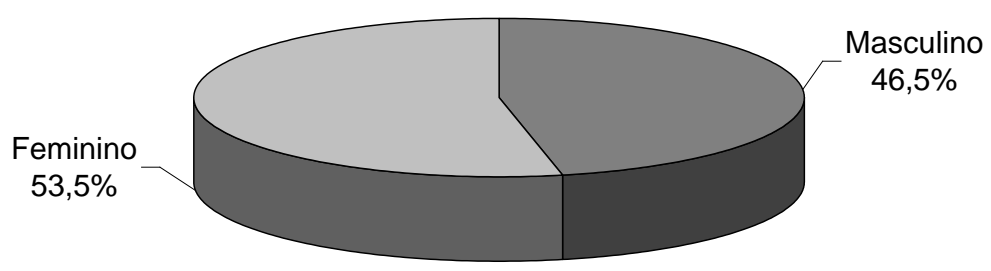

Fonte: Elaboração própria

A Figura 1 demonstrou que $53,5 \%$ dos clientes são do sexo feminino. Através da Figura 2 pode-se observar que a faixa-etária predominante foi de 24 a 28 anos, 
com 24,6\% e de 29 a 33 com 23,1\%. No que diz respeito à escolaridade, a maior parte dos clientes possuem ensino superior completo com 32,7\% e ensino médio completo com $23,5 \%$. Em relação à renda familiar, as informações fornecidas pelos clientes revelaram que a maior parte dos consumidores concentra-se de $R \$ 2.000,00$ a $R \$$ $4.000,00$ e acima de $R \$ 4000,00$.

No aspecto frequência de visita em relação a estabelecimentos do ramo, os dados mostram que $21,5 \%$ dos clientes frequentam o restaurante de duas a três vezes por semana e $19,6 \%$ duas a três vezes por mês. Quando questionados sobre a indicação dos serviços que a empresa oferece as outras pessoas, 99,23\% responderam "Sim" e 100\% dos clientes retornariam ao estabelecimento.

\subsection{Análise de Confiabilidade}

Utilizou-se o Alpha de Cronbach, a fim de verificar a confiabilidade do instrumento de pesquisa. A Tabela 1 apresenta o resumo da tabulação dos dados coletados, com os resultados do somatório das variâncias para cada item e o somatório da variância da soma das respostas de cada entrevistado.

\begin{tabular}{llllll}
\multicolumn{2}{l}{ Tabela 1 - Análise do Alpha de Cronbach } \\
\hline Entrevistado & Q1 & Q2 & $\ldots$ & Q59 & TOTAL \\
\hline 1 & 4 & 4 & $\ldots$ & 1 & 227,00 \\
2 & 4 & 5 & $\ldots$ & 3 & 210,00 \\
3 & 5 & 5 & $\ldots$ & 4 & 271,51 \\
4 & 4 & 4 & $\ldots$ & 4 & 233,91 \\
$\ldots$ & $\ldots$ & $\ldots$ & $\ldots$ & $\ldots$ & $\ldots$ \\
260 & 5 & 4 & $\ldots$ & 5 & 281,00 \\
\hline \multirow{2}{*}{$\mathrm{s}^{2}$} & 0,357 & 0,480 & $\ldots$ & 0,817 & \\
& $\sum_{i=1}^{k} s_{i}^{2}=$ & & & \\
\end{tabular}

Fonte: Elaboração Própria 
Figura 2 - Perfil dos respondentes

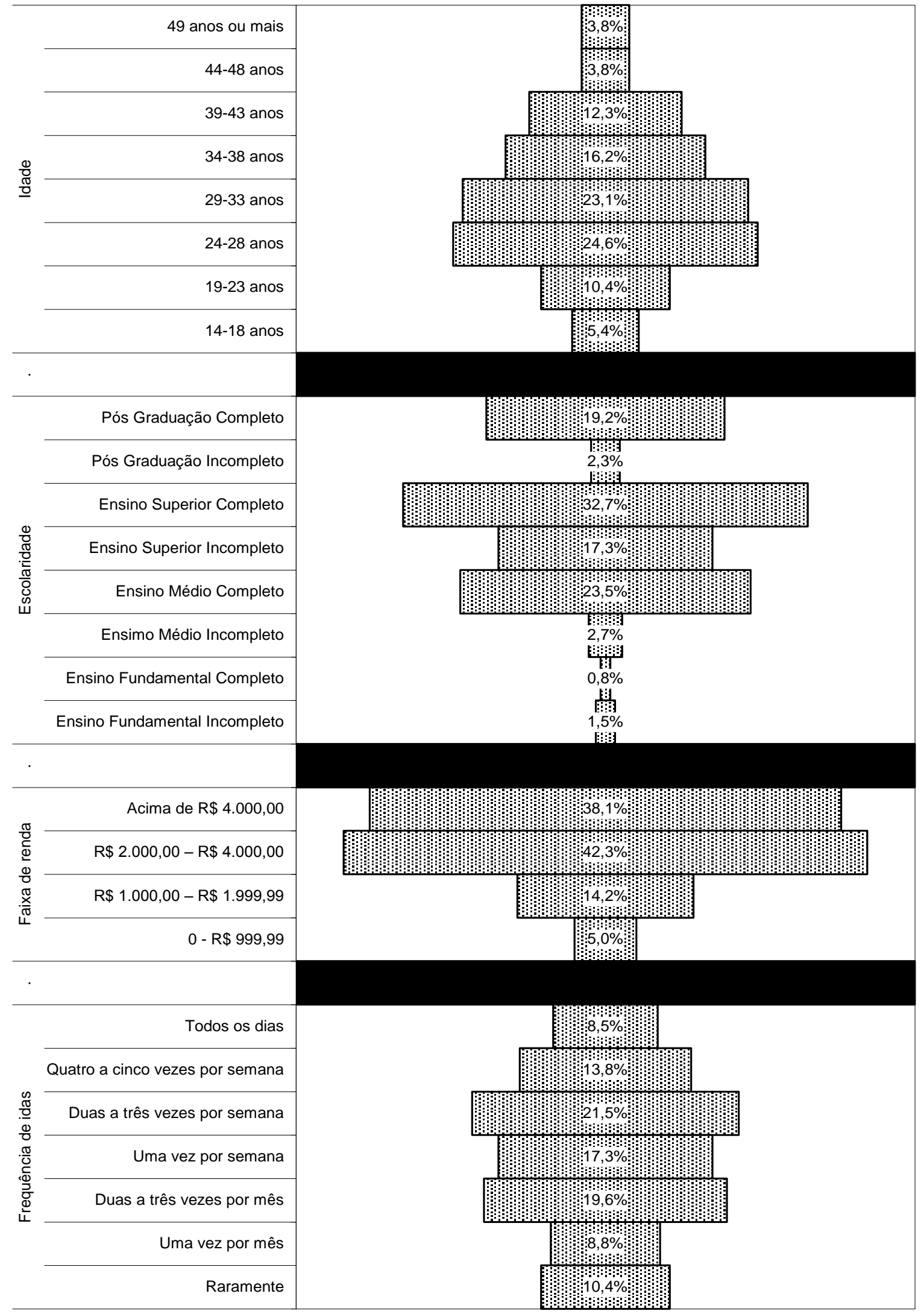

Fonte: Elaboração própria 
Assim, aplicando-se a fórmula do alfa de Cronbach, chegou-se ao valor de $96,1 \%$, conforme demonstra a equação abaixo:

$$
\alpha=\left(\frac{\mathrm{k}}{\mathrm{k}-1}\right) \cdot\left(1-\frac{\sum_{\mathrm{i}=1}^{\mathrm{k}} \mathrm{s}_{\mathrm{i}}^{2}}{\mathrm{~s}_{\mathrm{t}}^{2}}\right)=\left(\frac{59}{59-1}\right) \cdot\left(1-\frac{40,725}{738,31}\right)=96,1 \%
$$

A partir do valor obtido para o alfa de Cronbach, pode-se observar que os resultados obtidos através dos questionários para avaliar a satisfação dos clientes do Restaurante Albinos têm uma confiabilidade muito alta.

\subsection{Análise por Dimensão}

Os 59 indicadores de qualidade trabalhados no estudo formam 15 dimensões. Entre elas estão as dimensões proposta por Parasuraman et al. (1988) conforme apresentado na parte teórica deste trabalho, e dimensões/itens referentes a aspectos atuais do setor de restaurantes.

A dimensão de qualidade dos serviços que apresentou índice mais elevado no restaurante pesquisado foi Qualidade do produto, com média igual a 4,48. As dimensões Ações ambientais, Acessibilidade para portadores de necessidades especiais e Equipamentos eletrônicos possuem média inferior a 4, as médias das dimensões são respectivamente $3,89,3,78$ e 3,70, como pode ser observado na Figura 3 , com os resultados em ordem decrescente.

Figura 3 - Resultados das Dimensões

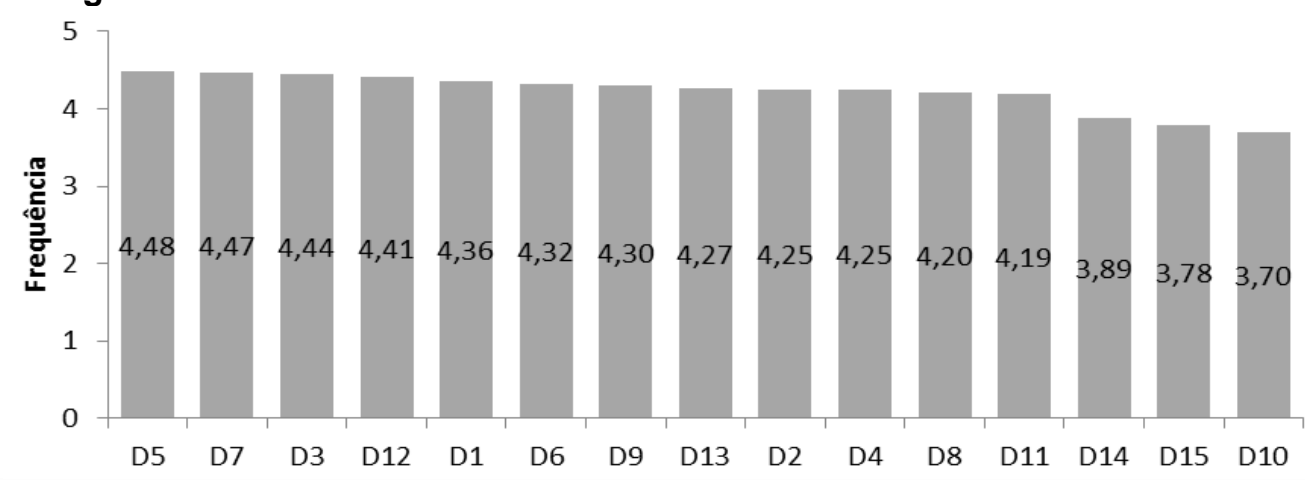

Fonte: Elaboração Própria

D5: Qualidade do produto; D7: Limpeza; D3: Segurança; D12: Colaboradores; D1: Confiabilidade; D9: Layout; D6: Condições do ambiente; D13: Utensílios de mesa; D2: Receptividade; D4: Empatia; D8: Instalações; D11: Conforto do Assento; D14: Ações ambientais; D15: Acessibilidade; D10: Equipamentos Eletrônicos. 


\subsection{Comparação entre os Itens}

A Figura 4 representa em ordem decrescente os itens da pesquisa com suas respectivas médias, indicando os que foram mais bem avaliados e os que tiveram resultados inferiores segundo a percepção do cliente. 
Figura 4 - Média dos itens e respectivos erros padrão

Grau de concordância (médias e erros-padrão)

29. Este restaurante mantém as entradas e as saídas limpas $(n=257)$

21. O restaurante serve comida saborosa $(n=259)$

22. O restaurante oferece comida fresca $(n=259)$

30. No geral, este restaurante é mantido limpo $(n=259)$

28. Este restaurante mantém o self - service organizado e limpo $(n=259)$

12. Os colaboradores do restaurante são corteses com você $(n=254)$

19. A qualidade dos alimentos é visivelmente atraente $(n=257)$

10. O comportamento dos colaboradores transmite confiança aos clientes $(n=255)$

24. A temperatura neste restaurante é confortável $(n=259)$

11. Você se sente seguro com os alimentos e serviços prestados pelo restaurante $(n=260)$

48. Um adequado número de colaboradores me faz sentir bem atendido $(n=253)$

13. Os colaboradores do restaurante possuem conhecimento para responder suas perguntas $(n=243)$

20. O restaurante oferece opções saudáveis $(n=260)$

1. O restaurante realiza o serviço no prazo prometido $(n=241)$

46. Os colaboradores são bem vestidos e arrumados $(n=257)$

3. O restaurante executa o serviço correto pela primeira vez $(n=241)$

4. O restaurante registra os pedidos e as contas sem erros $(n=243)$

15. O horário de funcionamento do restaurante é conveniente para o consumidor $(n=251)$

47. Os colaboradores me fazem sentir bem $(n=257)$

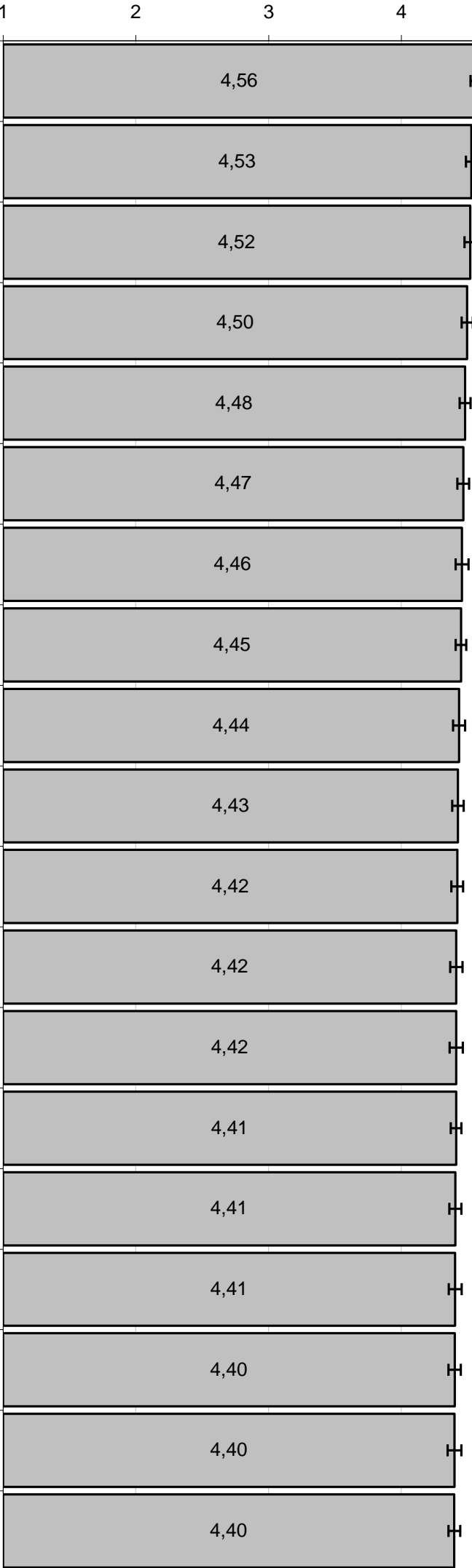


49. Vidros, pratos, talheres são de qualidade $(n=259)$

8. Os colaboradores do restaurante estão sempre dispostos a ajudá-lo $(n=253)$

25. O aroma no restaurante é agradável $(n=258)$

38. É fácil caminhar no ambiente deste restaurante e encontrar o que procura $(n=255)$

7. Os colaboradores do restaurante o atendem com rapidez $(n=255)$

36. Neste restaurante, nos corredores entre as mesas há espaço suficiente para se movimentar com facilidade $(n=258)$

17. O restaurante possui o melhor interesse em atendê-lo $(n=250)$

27. Este restaurante mantém os banheiros limpos $(n=247)$

45. É fácil entrar e sair dos seus lugares no restaurante $(n=258)$

39. O número de mesas torna o ambiente deste restaurante fácil de caminhar $(n=258)$

2. Quando você tem um problema, o restaurante mostra um interesse sincero em resolvê-lo $(n=225)$

5. Os colaboradores do restaurante apresentam o cardápio com informações claras e corretas $(n=233)$

34. Mobiliário (mesa, cadeira) são de qualidade $(\mathrm{n}=256)$

23. O nível de iluminação do restaurante é adequado $(n=258)$

35. Estacionamento (existência e tamanho das vagas, espaço para manobra) $(n=238)$

43. A cadeira deste restaurante permite-me sentar a uma distância confortável $(n=258)$

18. Os colaboradores do restaurante entendem suas necessidades específicas $(n=242)$

26. O som no ambiente faz do restaurante um lugar agradável $(n=258)$

37. A sinalização no ambiente deste restaurante oferece orientação adequada $(\mathrm{n}=252)$

14. O restaurante lhe dá atenção individual $(n=244)$

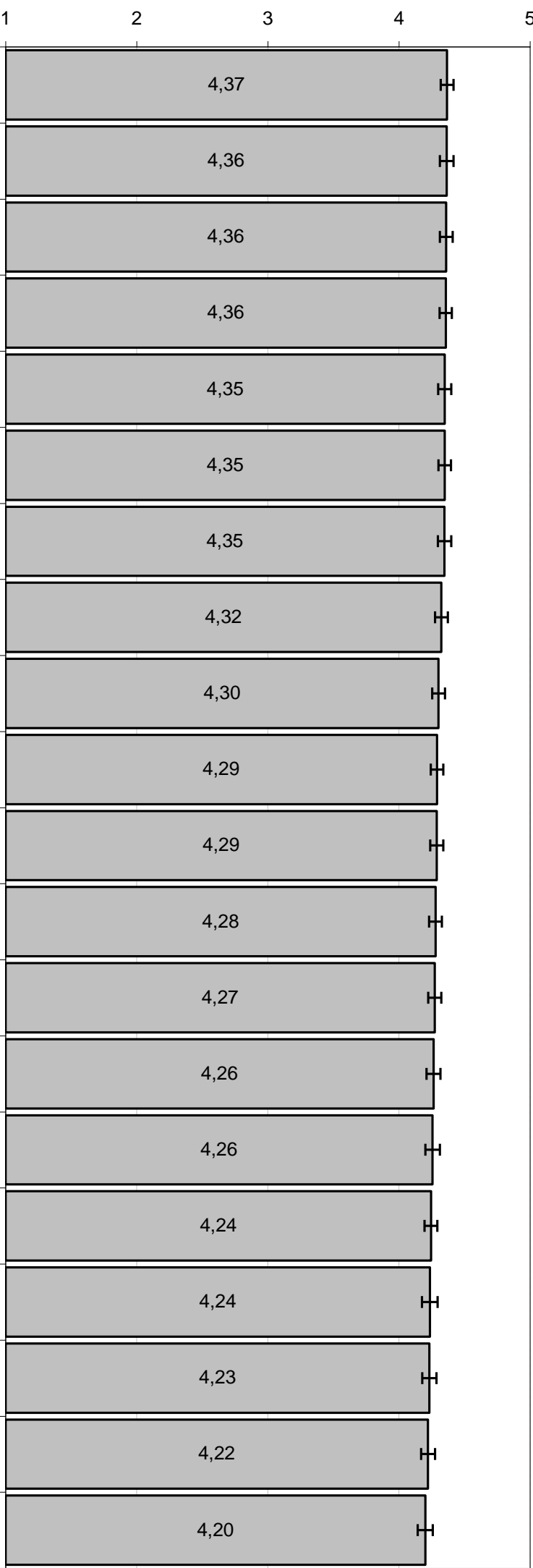

Grau de concordância (médias e erros-padrão) 
31. O design das instalações torna o restaurante atraente $(n=253)$

33. As cores utilizadas criam um ambiente acolhedor

50. Toalhas de mesa, guardanapos são atraentes $(n=257)$

6. Os colaboradores do restaurante dizem exatamente em quanto tempo os serviços serão realizados.

9. Os colaboradores do restaurante nunca estão ocupado para atender suas solicitações $(n=247)$

32. A decoração do restaurante é atraente.

16. O restaurante tem colaboradores que lhe dão atenção personalizada $(n=241)$

44. Assentos deste restaurante são confortáveis

56. Banheiros adaptados $(n=214$

52. Equipamentos de controles de desperdício (Sensores de iluminação e água)

59. Funcionários capacitados para atender as necessidades especiais $(n=193)$

51. Controle de resíduos gerados (exemplo coleta seletiva).

55. Circulação (mobiliário e pisos adequados, rebaixamento das calçadas) $(n=214)$

40. O aparelho (TV) faz deste restaurante interessante.

53. Divulgação das informações relacionadas à questão ambiental $(n=174)$

54. Acesso (através de rampas, escadas, corrimão, elevador, piso tátil).

42. O aparelho (TV) contribui para diversão $(n=245)$

57. Comunicação (sinalização para sanitários, rotas (no sentido de deslocamento), cardápios adaptados (Braille).

41. O aparelho (TV) adiciona 'emoção' ao local ( $n=247$

58. Estacionamento com vagas reservadas.

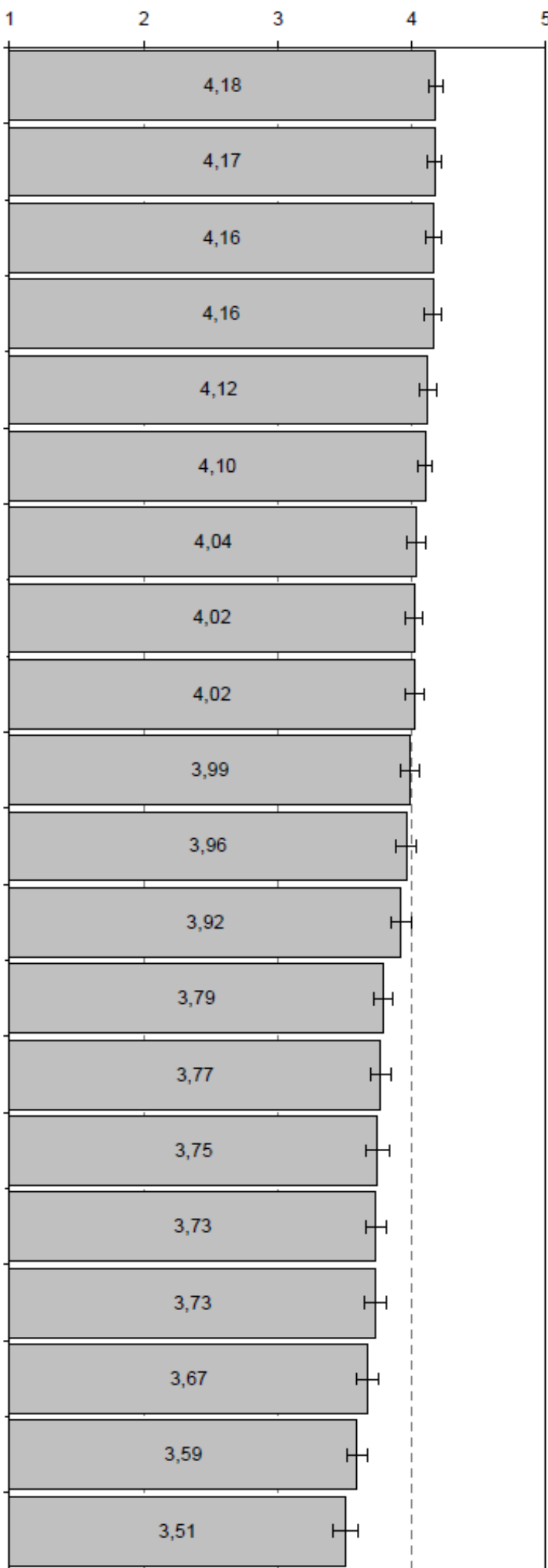

Fonte: Elaboração Própria

Revista Produção Online. Florianópolis, SC, v. 19, n. 3, p. 784-810, 2019 


\subsection{Correlações com a Satisfação Geral}

O valor de r é um auxílio para descobrir quais os itens precisam ser priorizados, caso apresentem médias inferiores, para que a nota geral da satisfação tenha uma melhora significativa, ou seja, quanto maior o valor de $r$, maior a correlação do item respectivo com a nota da satisfação geral do cliente.

Onde $r=$ coeficiente de correlação $(-1 a+1) ; P=$ nível de significância (tem que ser menor do que 0,05 para ser significativo), todos os itens foram significativos.

Tabela 2 - Correlação dos itens

(continua)

\begin{tabular}{|c|c|c|c|c|}
\hline \multirow{2}{*}{ DIMENSAO / ITEM } & \multicolumn{2}{|c|}{$\begin{array}{c}\text { Grau de } \\
\text { Concordância }\end{array}$} & \multicolumn{2}{|c|}{ Correlação } \\
\hline & Médiasıerros & $\mathrm{n}$ & $r$ & $\mathrm{P}$ \\
\hline 47. Os colaboradores me fazem sentir bem. & $4,40 \pm 0,04$ & 257 & 0,48 & 0,0001 \\
\hline 59. Funcionários capacitados para atender as necessidades especiais. & $3,96 \pm 0,08$ & 193 & 0,47 & 0,0001 \\
\hline 50. Toalhas de mesa, guardanapos são atraentes. & $4,16 \pm 0,06$ & 257 & 0,46 & 0,0001 \\
\hline 49. Vidros, pratos, talheres são de qualidade. & $4,37 \pm 0,05$ & 259 & 0,45 & 0,0001 \\
\hline 26. O som no ambiente faz do restaurante um lugar agradável. & $4,23 \pm 0,05$ & 258 & 0,41 & 0,0001 \\
\hline 44. Assentos deste restaurante são confortáveis. & $4,02 \pm 0,06$ & 257 & 0,41 & 0,0001 \\
\hline 22. O restaurante oferece comida fresca. & $4,52 \pm 0,04$ & 259 & 0,4 & 0,0001 \\
\hline 46. Os colaboradores são bem vestidos e arrumados. & $4,41 \pm 0,05$ & 257 & 0,39 & 0,0001 \\
\hline 56. Banheiros adaptados. & $4,02 \pm 0,07$ & 214 & 0,39 & 0,0001 \\
\hline 48. Um adequado número de colaboradores me faz sentir bem atendido. & $4,42 \pm 0,04$ & 253 & 0,38 & 0,0001 \\
\hline $\begin{array}{l}\text { 37. A sinalização no ambiente deste restaurante oferece orientação } \\
\text { adequada. }\end{array}$ & $4,22 \pm 0,05$ & 252 & 0,38 & 0,0001 \\
\hline 41. O aparelho (TV) adiciona 'emoção' ao local. & $3,59 \pm 0,08$ & 247 & 0,38 & 0,0001 \\
\hline $\begin{array}{l}\text { 36. Neste restaurante, nos corredores entre as mesas há espaço suficiente } \\
\text { para se movimentar com facilidade. }\end{array}$ & $4,35 \pm 0,05$ & 258 & 0,37 & 0,0001 \\
\hline 45. É fácil entrar e sair dos seus lugares no restaurante. & $4,30 \pm 0,05$ & 258 & 0,37 & 0,0001 \\
\hline $\begin{array}{l}\text { 39. O número de mesas torna o ambiente deste restaurante fácil de } \\
\text { caminhar. }\end{array}$ & $4,29 \pm 0,05$ & 258 & 0,37 & 0,0001 \\
\hline 42. O aparelho (TV) contribui para diversão. & $3,73 \pm 0,08$ & 245 & 0,37 & 0,0001 \\
\hline 54. Acesso (através de rampas, escadas, corrimão, elevador, piso tátil). & $3,73 \pm 0,07$ & 218 & 0,37 & 0,0001 \\
\hline $\begin{array}{l}\text { 57. Comunicação (sinalização para sanitários, rotas (no sentido de } \\
\text { deslocamento), cardápios adaptados (Braille). }\end{array}$ & $3,67 \pm 0,08$ & 203 & 0,37 & 0,0001 \\
\hline 31. O design das instalações torna o restaurante atraente. & $4,18 \pm 0,05$ & 253 & 0,35 & 0,0001 \\
\hline 55. Circulação (mobiliário e pisos adequados, rebaixamento das calçadas). & $3,79 \pm 0,07$ & 214 & 0,35 & 0,0001 \\
\hline 7. Os colaboradores do restaurante o atendem com rapidez. & $4,35 \pm 0,05$ & 255 & 0,34 & 0,0001 \\
\hline 20. O restaurante oferece opções saudáveis. & $4,42 \pm 0,05$ & 260 & 0,33 & 0,0001 \\
\hline 14. O restaurante Ihe dá atenção individual. & $4,20 \pm 0,06$ & 244 & 0,33 & 0,0001 \\
\hline 16. O restaurante tem colaboradores que Ihe dão atenção personalizada. & $4,04 \pm 0,07$ & 241 & 0,33 & 0,0001 \\
\hline 40. O aparelho (TV) faz deste restaurante interessante. & $3,77 \pm 0,08$ & 249 & 0,33 & 0,0001 \\
\hline
\end{tabular}




\section{DIMENSAO / ITEM}

\section{Grau de Concordância}

Médiasterros

38. É fácil caminhar no ambiente deste restaurante e encontrar o que procura.

25. O aroma no restaurante é agradável.

9. Os colaboradores do restaurante nunca estão ocupados para atender suas solicitações.

32. A decoração do restaurante é atraente.

19. A qualidade dos alimentos é visivelmente atraente.

18. Os colaboradores do restaurante entendem suas necessidades específicas.

33. As cores utilizadas criam um ambiente acolhedor.

52. Equipamentos de controles de desperdício (Sensores de iluminação e água).

8. Os colaboradores do restaurante estão sempre dispostos a ajudá-lo.

27. Este restaurante mantém os banheiros limpos.

21. O restaurante serve comida saborosa.

13. Os colaboradores do restaurante possuem conhecimento para responder suas perguntas.

17. O restaurante possui o melhor interesse em atendê-lo.

34. Mobiliário (mesa, cadeira) são de qualidade.

6. Os colaboradores do restaurante dizem exatamente em quanto tempo os serviços serão realizados.

53. Divulgação das informações relacionadas à questão ambiental.

43. A cadeira deste restaurante permite-me sentar a uma distância confortável.

30. No geral, este restaurante é mantido limpo.

28. Este restaurante mantém o self - service organizado e limpo.

12. Os colaboradores do restaurante são corteses com você.

11. Você se sente seguro com os alimentos e serviços prestados pelo restaurante.

51. Controle de resíduos gerados (exemplo coleta seletiva).

29. Este restaurante mantém as entradas e as saídas limpas.

3. O restaurante executa o serviço correto pela primeira vez.

1. O restaurante realiza o serviço no prazo prometido.

2. Quando você tem um problema, o restaurante mostra um interesse sincero em resolvê-lo.

5. Os colaboradores do restaurante apresentam o cardápio com informações claras e corretas.

58. Estacionamento com vagas reservadas.

35. Estacionamento (existência e tamanho das vagas, espaço para manobra).

24. A temperatura neste restaurante é confortável.

10. O comportamento dos colaboradores transmite confiança aos clientes.

15. O horário de funcionamento do restaurante é conveniente para o consumidor.

23. O nível de iluminação do restaurante é adequado.

4. O restaurante registra os pedidos e as contas sem erros.
Correlação

$4,36 \pm 0,05 \quad 255 \quad 0,31 \quad 0,0001$

$4,36 \pm 0,05 \quad 258 \quad 0,31 \quad 0,0001$

$4,12 \pm 0,06 \quad 247 \quad 0,31 \quad 0,0001$

$4,10 \pm 0,05 \quad 252 \quad 0,31 \quad 0,0001$

$4,46 \pm 0,05 \quad 257 \quad 0,3 \quad 0,0001$

$\begin{array}{llll}4,24 \pm 0,06 & 242 & 0,3 & 0,0001\end{array}$

$4,17 \pm 0,05 \quad 256 \quad 0,3 \quad 0,0001$

$3,99 \pm 0,07 \quad 184 \quad 0,3 \quad 0,0001$

$\begin{array}{llll}4,36 \pm 0,05 & 253 & 0,29 & 0,0001\end{array}$

$\begin{array}{llll}4,32 \pm 0,05 & 247 & 0,29 & 0,0001\end{array}$

$4,53 \pm 0,04 \quad 259 \quad 0,28 \quad 0,0001$

$\begin{array}{llll}4,42 \pm 0,05 & 243 & 0,28 & 0,0001\end{array}$

$\begin{array}{llll}4,35 \pm 0,05 & 250 & 0,28 & 0,0001\end{array}$

$\begin{array}{llll}4,27 \pm 0,05 & 256 & 0,28 & 0,0001\end{array}$

$\begin{array}{llll}4,16 \pm 0,06 & 219 & 0,28 & 0,0001\end{array}$

$3,75 \pm 0,08 \quad 174 \quad 0,28 \quad 0,0001$

$4,24 \pm 0,05 \quad 258 \quad 0,27 \quad 0,0001$

$\begin{array}{llll}4,50 \pm 0,04 & 259 & 0,26 & 0,0001\end{array}$

$\begin{array}{llll}4,48 \pm 0,04 & 259 & 0,26 & 0,0001\end{array}$

$4,47 \pm 0,04 \quad 254 \quad 0,25 \quad 0,0001$

$4,43 \pm 0,04 \quad 260 \quad 0,25 \quad 0,0001$

$\begin{array}{llll}3,92 \pm 0,07 & 177 & 0,25 & 0,0003\end{array}$

$4,56 \pm 0,04 \quad 257 \quad 0,24 \quad 0,0001$

$\begin{array}{llll}4,41 \pm 0,05 & 241 & 0,24 & 0\end{array}$

$4,41 \pm 0,04 \quad 241 \quad 0,24 \quad 0,0001$

$\begin{array}{llll}4,29 \pm 0,05 & 225 & 0,24 & 0,0001\end{array}$

$\begin{array}{llll}4,28 \pm 0,05 & 233 & 0,24 & 0,0001\end{array}$

$3,51 \pm 0,09 \quad 192 \quad 0,24 \quad 0,0003$

$\begin{array}{llll}4,26 \pm 0,06 & 238 & 0,23 & 0,0001\end{array}$

$\begin{array}{llll}4,44 \pm 0,05 & 259 & 0,20 & 0,0007\end{array}$

$\begin{array}{llll}4,45 \pm 0,04 & 255 & 0,17 & 0,003\end{array}$

$\begin{array}{llll}4,40 \pm 0,05 & 251 & 0,17 & 0,0029\end{array}$

$\begin{array}{llll}4,26 \pm 0,05 & 258 & 0,16 & 0,0055\end{array}$

$4,40 \pm 0,05 \quad 243 \quad 0,15 \quad 0,0114$

Fonte: Elaboração Própria

Revista Produção Online. Florianópolis, SC, v. 19, n. 3, p. 784-810, 2019 
Segundo a tabela 2, o item que apresentou maior correlação com a nota da satisfação geral foi o que se refere o quão bem os colaboradores fazem o cliente se sentir. Nesse caso, como o item teve uma média significativa, indica que o restaurante está no caminho certo, atendendo as prioridades dos clientes. Mesmo assim, é importante manter a qualidade em busca de melhorias para idealizá-los e obter notas cada vez maiores.

Já o segundo resultado, sobre funcionários capacitados para atender necessidades especiais, obteve uma correlação alta e uma média mais baixa. O que significa que esse quesito deve ser priorizado ao implementar melhorias e como sugestão, o restaurante poderia promover dias de treinamentos, dispor de pessoas experientes para auxilio dos funcionários, entre outros.

Dentro desse contexto, retira-se 7 itens para trabalhar a sugestão de melhorias dentro do restaurante.

Tabela 3- Principais itens

\begin{tabular}{lcc}
\multicolumn{1}{c}{ Item referente } & Média & R \\
\hline 59. Funcionários capacitados para atender as necessidades especiais. & 3,96 & 0,47 \\
41. O aparelho (TV) adiciona 'emoção' ao local. & 3,59 & 0,38 \\
42. O aparelho (TV) contribui para diversão. & 3,73 & 0,37 \\
$\begin{array}{l}\text { 54. Acesso (através de rampas, escadas, corrimão, elevador, piso tátil). } \\
\text { 57. Comunicação (sinalização para sanitários, rotas (no sentido de deslocamento), }\end{array}$ & 3,73 & 0,37 \\
cardápios adaptados (Braille). & 3,67 & 0,37 \\
55. Circulação (mobiliário e pisos adequados, rebaixamento das calçadas). & 3,79 & 0,35 \\
40. O aparelho (TV) faz deste restaurante interessante. & 3,77 & 0,33 \\
\hline
\end{tabular}

Fonte: Elaboração própria

Observa-se que duas dimensões foram mais problemáticas de acordo com os resultados obtidos, são elas: Equipamentos Eletrônicos e Acessibilidade para portadores de necessidades especiais.

No caso da Acessibilidade, constatou-se que realmente faltam recursos para atender esse público em determinados aspectos, porém, o restaurante dispõe de banheiros adaptados, rampas, corrimãos nas entradas e saídas e pelo self-service.

Em equipamentos eletrônicos, há concordância que a TV é um objeto comum dentro do espaço, mas devido sua alta correlação com a nota da satisfação geral, sugere-se que o restaurante trabalhe uma forma de destaque para a TV, que atenda as expectativas e possa proporcionar um ambiente mais agradável aos clientes. 
Quanto à dimensão Ações Ambientais, embora a correlação com a satisfação geral tenha sido menor, é importante salientar que a necessidade de preocupação com esse item deve ser redobrada devido à realidade do mundo atual, pois aos poucos os clientes estão percebendo a importância da 'consciência verde' e preferindo produtos ou serviços que tenha seu foco também voltado para questões ambientais. O restaurante estudado apresenta sensores de energia e água, coleta seletiva de óleo, garrafa pet e latas, porém não são divulgados. A empresa poderia conscientizar as pessoas a partir do exemplo que ela pratica e futuramente investir cada vez mais em meios de diminuir os impactos que o consumismo gera no decorrer dos anos.

\section{CONSIDERAÇÕES}

No decorrer do presente trabalho procurou-se demonstrar a importância do marketing como ferramenta de entrega de valor em busca da satisfação do cliente. Sendo assim, é essencial agregar diferenciais de valor em seus serviços que atendam as necessidades, desejos e expectativas dos clientes.

A avaliação da qualidade dos serviços oferecidos pelo restaurante é um procedimento fundamental para os proprietários e gestores dos estabelecimentos, a fim de obter informações a respeito da qualidade percebida segundo a percepção dos clientes, além de contribuir para uma melhoria da gestão do restaurante.

Outro ponto importante, é que apesar de ser um estudo de caso a metodologia e os resultados encontrados servem com um norte para o desenvolvimento de trabalhos similares na área de qualidade e serviço. Vale lembrar que atualmente o setor de serviço é o que mais contribui para o PIB brasileiro. Sendo assim é importante para um engenheiro de produção conhecer e dominar técnicas que vão além do processo de produção fabril.

O trabalho adotou a ferramenta DINNERPERF proposta por Barros (2013), para avaliar e classificar a qualidade dos serviços prestados pelo restaurante Albinos. Por meio do estudo de caso realizado e a aplicação do o emprego do modelo adotado foi possível:

Identificar o perfil dos clientes: Os resultados mostram que o quantitativo de mulheres destaca-se nos estabelecimento avaliado, com 53,35\%. A faixa-etária predominante foi entre 24 a 28 anos, com $24,6 \%$. A respeito do questionamento sobre a escolaridade, a maior parte da amostra é composta por clientes que possuem Ensino 
Superior completo, sendo $32,7 \%$ dos clientes. Em relação às informações fornecidas pelos clientes sobre a faixa salarial verificou-se que $42,3 \%$ concentram-se de $R \$$ $2.000,00$ a $R \$ 4.000,00$. Em relação a frequência, $21,5 \%$ dos respondentes frequentam o restaurante de duas a três vezes por semana;

Obter a média geral de satisfação dos clientes, que foi de 4,23. E verificar se os clientes recomendariam e retornariam ao estabelecimento, $99,23 \%$ deles recomendariam o estabelecimento para outras pessoas e $100 \%$ dos clientes retornariam ao restaurante;

Mensurar a confiabilidade do modelo: Através do alfa de Cronbach, que verificou que $o$ instrumento de pesquisa tem uma confiabilidade muito alta;

Destacar as dimensões e os itens mais críticos: A fim de que estes fossem corrigidos e melhorados. Percebeu-se que os itens considerados mais críticos e por isso, possuem uma maior prioridade para ações de melhorias. As dimensões e os itens mais críticos foram: Ações ambientais $\left(Q_{51}\right.$ - Controle de resíduos gerados, $Q_{52}$ - Equipamentos de controles de desperdício, Q53 - Divulgação das informações relacionadas à questão ambiental), Acessibilidade para portadores de necessidades especiais (Q54 - Acesso, Q 55 - Circulação, Q57 - Comunicação, $Q_{58}$ - Estacionamento com vagas reservadas e Q59 - Funcionários capacitados para atender as necessidades especiais) e Equipamentos eletrônicos ( $Q_{40}-O$ aparelho (TV) faz deste restaurante interessante, $Q_{41}$ - O aparelho (TV) adiciona 'emoção' ao local, $Q_{42}$ - O aparelho (TV) contribui para diversão).

Analisar a correlação de cada item com a satisfação geral, a fim de melhorar e maximizar a satisfação dos clientes nos itens que mais interferem na satisfação geral. Os itens que mais se correlacionam com a satisfação geral, são respectivamente: $Q_{47}$ - Os colaboradores me fazem sentir bem, $Q_{59}$ - Funcionários capacitados para atender as necessidades especiais, Q50 - Toalhas de mesa, guardanapos são atraentes, Q49 - Vidros, pratos, talheres são de qualidade, $Q_{26}$ - O som no ambiente faz do restaurante um lugar agradável, $Q_{44}$ - Assentos deste restaurante são confortáveis e $Q_{22}$ - O restaurante oferece comida fresca. O item $Q_{59}$ não possui uma média satisfatória, portanto, deve ser prioridade em ações de melhorias.

Os resultados obtidos e possíveis soluções foram informados aos gestores do estabelecimento, foi sugerido aos gestores que a empresa divulgasse as ações 
ambientais já adotadas, buscassem por medidas sustentáveis e criassem uma política ambiental a ser seguida. Investisse em treinamento dos colaboradores, aumentasse a sinalização e separasse uma vaga para portadores de necessidades especiais. Essas informações têm intuito de aprimorar os serviços prestados, fazendo com que o estabelecimento consiga atingir excelência na prestação de serviços, através da conscientização sobre a opinião de seus clientes e do reconhecimento de seus pontos fracos, para buscar a melhoria contínua.

\section{REFERÊNCIAS}

ALBRECHT, K. Revolução nos serviços. São Paulo: Pioneira, 1992.

ALBRECHT, K. Serviços internos. 3. ed. São Paulo: Thomson, 2004.

BARROS, M. Dinnerperf: um modelo para avaliação e classificação da qualidade de serviços em restaurantes segundo a Percepção dos clientes. Campos dos Goytacazes, 2013.

BALTA, Sabah. The influence of internal marketing on employee satisfaction in the service industry. Business Management Dynamics, v. 8, n. 1, p. 12, 2018.

CHIAVENATO, I. Administração de recursos humanos: fundamentos básicos. 4.ed. São Paulo: Atlas, 2005.

COBRA, M. Marketing básico: uma perspectiva brasileira. São Paulo: Atlas, 2007.

COBRA, M.; RIBEIRO, Á. Marketing: magia e sedução. São Paulo: Cobra, 2000.

CRONBACH, L. J. Coefficient Alpha and the Internal Structure of Tests. Psychometrika, v. 16, n. 3, p. 297-334, 1951. https://doi.org/10.1007/BF02310555

CRONIN, J.; TAYLOR, S. Measuring service quality: A reexamination and extension. Journal of Marketing, v. 56, n. 3, p. 55-68, 1992.

https://doi.org/10.1177/002224299205600304

FITZSIMMONS, J. A.; FITZSIMMONS, M. J. Administração de serviços: operações, estratégias e tecnologia de informações. 2. ed. Porto Alegre: Bookman, 2000.

FITZSIMMONS, J. A.; FITZSIMMONS, M. J. Administração de serviços: operações, estratégia e tecnologia da informação. 6. ed. Porto Alegre: Bookman, 2011.

FREITAS, A.L.P.; RODRIGUES, S.G. A avaliação da confiabilidade de questionários: uma análise utilizando o coeficiente alpha de Cronbach. In: SIMPEP - SIMPOSIO DE ENGENHARIA DE PRODUÇÃO, 12., 2005. Anais [....]. Bauru, SP, 2005.

GIL, A. C. Pesquisa em economia. São Paulo. Atlas, 1988. 
KOTLER, P. A edição do novo milênio. Tradução por Bazan Tecnologia e Lingüística. 10. ed. São Paulo: Prentice Hall, 2000.

KOTLER, P. Administração de marketing. 5. ed. São Paulo: Atlas, 1998.

KOTLER, P.; ARMSTRONG, G. Introdução ao marketing. Rio de Janeiro: LTC, 1997.

KOTLER, P.; KELLER, K. Administração de marketing. 12. ed. São Paulo: Pearson

Prentice Hall, 2006.

LAS CASAS, A. - Marketing: conceitos, exercícios, casos. 8. ed. São Paulo: Atlas, 2009.

MALHOTRA, N. K. Pesquisa de marketing: uma orientação aplicada. 4. ed. Porto Alegre: Bookman, 2006.

MASLOW, A. Motivation and personality. Nova York: Harper \& Row, 1954.

PARASURAMAN, A.; ZEITHAML V. A.; BERRY, L. L. SERVQUAL: A multiple-item scale for measuring consumer perceptions of ser vice quality. Journal of Retailing, v. 64, n. 1, p. 1240,1988 .

PELLIM, F.; MASHIBA, G.; SANTOS, P. A Entrega de valor como ferramenta de inovação em serviços de atendimento ao cliente. Monografia (Trabalho de graduação) Bauru, 2010. Disponível em:

<http://www.spositoonline.com.br/imagens/professor/gisele,frank e priscila monografia.pdf > Acesso em: 20 mar. 2016.

PORTER, M. E. Competição: estratégias competitivas essenciais. Rio de Janeiro: Campus, 1999.

SCHULZE, C.; SKIERA, B.; WIESEL, T. Linking customer and financial metrics to shareholder value: The leverage effect in customer-based valuation. Journal of Marketing, v. 76, n. 2, p. 17-32, 2012. https://doi.org/10.1509/jm.10.0280

SILVA, E. L.; MENEZES, E. M. Metodologia da pesquisa e elaboração de dissertação. 4. ed. Florianópolis: UFSC, 2005.

TEBOUL, J. Serviços em cena. Brasília: IEL/NC, 2008.

WHITELEY, R. C. A empresa totalmente voltada para o cliente: do planejamento a ação. Rio de Janeiro: Campus, 1992.

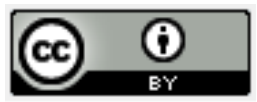

Artigo recebido em: 30/04/2018 e aceito para publicação em: 16/08/2019

DOI: http://dx.doi.org/10.14488/1676-1901.v19i3.3236 